\title{
Role of gap junctions in the contractile response to agonists in the mesenteric resistance artery of rats with acute hypoxia
}

\author{
HUAN LIU ${ }^{1,2^{*}}$, XIN-ZHI LI ${ }^{3 *}$, MIN PENG $^{1}$, WEI JI ${ }^{1}$, LEI ZHAO ${ }^{1,2,4}$, LI LI $^{1,4}$, \\ LIANG ZHANG $^{1,4}$, JUN-QIANG SI ${ }^{1,4}$ and KE-TAO MA ${ }^{1,4}$ \\ ${ }^{1}$ Department of Physiology; ${ }^{2}$ Centre of Medical Teaching Experiments; \\ ${ }^{3}$ Department of Pathophysiology and ${ }^{4}$ The Key Laboratory of Xinjiang Endemic and Ethnic Diseases, \\ Medical College of Shihezi University, Shihezi, Xinjiang 832002, P.R. China
}

Received November 15, 2015; Accepted December 21, 2016

DOI: $10.3892 / \mathrm{mmr} .2017 .6188$

\begin{abstract}
Hypoxic exposure results in the vascular dysfunction and reduction of vasomotor responses and thus disrupts or reduces blood flow in the resistance arteries. Connexin (Cx)-mediated gap junctional intercellular communication (GJIC) serves a critical role in the regulation of vasomotor tone and the synchronized contraction of arteries, however whether the adverse effect of hypoxia on vasomotor responses in vascular smooth muscle layer of resistance arteries is involved in changes in the GJIC and the expression of Cx43 and $\mathrm{Cx} 45$ remains to be elucidated. Pressure myography, whole-cell patch clamp and western blot analysis were used to investigate the differences in expression and function of gap junction (GJ) in the vascular smooth muscle cells (VSMCs) of the mesenteric resistance artery (MRA) from Sprague-Dawley (SD) rats in normoxia and acute hypoxia groups. In the present study, whole-cell patch clamp measurements demonstrated a significant reduction in the membrane capacitance and conductance in the VSMCs of the MRAs in the acute hypoxia (5 min) group $(n=13)$ compared with the normoxia group $(n=13)$, which suggested that exposure to acute hypoxia of 5 min decreased the coupling of the GJ between the VSMCs of MRAs in SD rats. Pressure myographic analysis demonstrated that 0.1-100 $\mu \mathrm{M}$ phenylephrine (PE)-induced MRA vasoconstriction was less sensitive under the acute hypoxic condition $(n=7)$ compared with the normoxia condition $(n=9)$ following treatment with $100 \mu \mathrm{M}$ 2-aminoethoxydiphenyl
\end{abstract}

Correspondence to: Dr Ke-Tao Ma or Dr Liang Zhang, Department of Physiology, Medical College of Shihezi University, 59 North 2nd Road, Shihezi, Xinjiang 832002, P.R. China

E-mail:maketao@hotmail.com

E-mail: zhangliang_0622@163.com

*Contributed equally

Key words: acute hypoxia, mesenteric resistance artery, gap junction, connexin43, connexin 45 borate for $20 \mathrm{~min}$. Compared with SD rats under normoxia, the PE-initiated vasoconstrictive frequency and amplitude under acute hypoxia for 20, 40 and $60 \mathrm{~min}$ in the MRAs of SD rats was markedly attenuated $(n=7)$. The results of western blot analysis indicated that the expression levels of Cx43 and Cx45 in MRA under acute hypoxia (1 h) were lower compared with normoxia. Cx43-and Cx45-mediated GJs serve a significant role in the regulation of the vasomotor function of MRA during hypoxia and may be essential for the adjustment of vasomotor tone in response to acute hypoxia.

\section{Introduction}

An adequate $\mathrm{O}_{2}$ supply via the vasculature is important for the normal function of the cardiovascular system (1). Reduced or impaired blood flow patterns in the larger conductance and resistance arteries are a factor in numerous pathological conditions that are associated with hypoxia-induced injury (2-4). It is known that acute hypoxia is associated with a number of cardiovascular diseases, including myocardial infarction (5), pulmonary hypertension $(6,7)$ and mesenteric ischemia (8) and thus leads to an increase in blood pressure together with peripheral vascular resistance due to reduction of tone in certain vascular beds and critical injury or death (4).

In general, vascular dysfunction and reduction of vasomotor tone by hypoxia/ischemia are characterized by abnormalities in intercellular communication, ion transport and the transport of biologically active substances between adjacent vascular smooth muscle cells (VSMCs) and vascular endothelial cells (ECs) (9). The gap junction (GJ) in the vasculature provides intercellular communication channels that permit the direct exchange of ions and small signaling molecules between neighboring cells and thus it is involved in the regulation of vasomotor tone and the coordination of vascular function by electrical and chemical coupling formed within and between the ECs and the VSMCs (9-11). The roles of the GJ are not confined to providing electrical coupling between neighboring cells; in various types of cells, the GJ serves a critical role in deciding cell survival vs. cell death under hypoxia/ischemia (12).

The GJ results from the docking of two hemichannels, which are formed by the assembly of six connexins 
(Cxs) $(10,13)$. Four isoforms of Cxs (Cx37, Cx40, Cx43 and $\mathrm{Cx} 45)$ are expressed in the vasculature of mammals, with the predominant expression of $\mathrm{Cx} 37$ and $\mathrm{Cx} 40$ in ECs and Cx43 and Cx45 in the VSMCs $(9,10)$. The present study identified that hypoxia/ischemia preconditioning in the heart suppresses electrical and chemical gap junctional intercellular communication (GJIC) of cardiomyocytes (14). The reduction of GJ coupling or GJ proteins in cardiomyocytes during hypoxia/ischemia is widely assumed to promote the development of arrhythmias (15). Several studies $(13,15-18)$ have identified different molecular mechanisms concerning the effect of hypoxia on GJIC, including a decline in expression in a time-dependent manner, dephosphorylation and redistribution of Cx43, the degradation of Cxs and the attenuation of endothelial adenosine triphosphate (ATP) release by hypoxic exposure. The present study on the actions of Cxs following exposure to hypoxic stresses focuses on the myocardium and astrocytes in the brain and vascular endothelial; however, the association between Cxs expression and Cxs functional involvement in the vascular smooth muscle layer of resistance arteries during hypoxia remains to be elucidated.

To address this question, using a well-defined in vitro hypoxic model, the present study investigated whether acute hypoxia suppresses the vasoconstriction of MRA in Sprague-Dawley (SD) rats and if vasoconstriction suppression is associated with the reduction of GJIC and Cx43/45 expression. The present study was performed to produce an improved understanding of the mechanisms involved in the change of vasomotor responses following acute hypoxia and to provide a hypothesis for the inhibition of expression and function of Cxs in MRAs during acute hypoxia conditions.

\section{Materials and methods}

Animals. Female and male 12-week-old SD rats (260-280 g; $\mathrm{n}=18$ ) supplied by Beijing Vital River Laboratory Animal Technology Co., Ltd. (license number: SCXK (BJ) 2012-0001), were used in the current study. All protocols were approved by the Institutional Animal Care and Use Committee at the Medical College of Shihezi University (Xinjiang, China) and were consistent with the Guidelines for the Care and Use of Laboratory Animals published by the US National Institutes of Health (Public Health Service Policy on Humane Care and Use of Animals, DHEW Publication No. 96-01, PHS Policy revised in 2002). Rats were anesthetized with an intramuscular injection $(1 \mathrm{ml} / \mathrm{kg})$ of a mixture of ketamine/xylazine/acepromazine (500/20/10 mg in $8.5 \mathrm{ml} \mathrm{H}_{2} \mathrm{O}$ ) (Sigma-Aldrich, Merck KGaA Millipore, Darmstadt, Germany) and subsequently rats were euthanized with an overdose of $100 \mathrm{mg} / \mathrm{kg}$ sodium pentobarbital (Sigma-Aldrich, Merck kGaA). The third-order branch of the MRA was harvested from the upper ileum mesentery and the surrounding connective and adipose tissue were removed for whole-cell patch clamp recordings, pressure myographic measurement and western blot analysis.

Hypoxia vascular model. An acute hypoxia model of MRA segments in vitro was established according to previous studies $(4,19,20)$. The rats were euthanized and the descending third-order branch of the MRA $(\sim 10 \mathrm{mg})$ was removed. The MRA segment was rinsed several times in PBS [composed of the following (g/l): $\mathrm{NaCl} 8.0, \mathrm{KCl} 0.2, \mathrm{KH}_{2} \mathrm{PO}_{4} 0.24, \mathrm{Na}_{2} \mathrm{HPO}_{4}$ 1.44; $\mathrm{pH}$ 7.4]. The connective adipose tissue surrounding the MRA and the endothelial cells was cleaned and the MRA rings ( $0.4 \mathrm{~mm}$ long, $200 \mathrm{~mm}$ in outer diameter) were immersed in DMEM/F12 medium with high glucose (Hyclone; GE Healthcare Bio Sciences, Pittsburgh, PA, USA) at $37^{\circ} \mathrm{C}$ for $24 \mathrm{~h}$ and then replaced with DMEM/F12 medium of low glucose (Hyclone; GE Healthcare Bio Sciences). Following hypoxia treatment for $5 \mathrm{~min}$ or $1 \mathrm{~h}$ at $37^{\circ} \mathrm{C}$ in a humidified atmosphere of $<3 \% \mathrm{O}_{2}, 5 \% \mathrm{CO}_{2}$ and $95 \% \mathrm{~N}_{2}$, the medium was replaced with PBS and the MRA rings were used in western blot analysis. The vascular normoxic group in this process was placed in an incubator at $37^{\circ} \mathrm{C}$. In the study by Nuñez et al (19), rings of pulmonary and systemic arteries obtained from rats were suspended in an organ bath $\left(37^{\circ} \mathrm{C}\right)$ containing Krebs solution and an atmosphere of $12 \% \mathrm{O}_{2}, 5 \% \mathrm{CO}_{2}$ and $83 \% \mathrm{~N}_{2}$, which produced an $\mathrm{O}_{2}$ concentration similar to that present in aortic blood. Hypoxia was induced by flooding with $95 \% \mathrm{~N}_{2}$ and $5 \% \mathrm{CO}_{2}$, which decreased the concentration of $\mathrm{O}_{2}$ in the bath to $\sim 5 \times 10^{-6} \mathrm{~mol} / 1$. In the experimental design of the present study, the hypoxia vascular model was induced by flooding the vessels with $5 \% \mathrm{O}_{2}, 90 \% \mathrm{~N}_{2}$ and $5 \% \mathrm{CO}_{2}$ or $2.5 \% \mathrm{O}_{2}, 92.5 \% \mathrm{~N}_{2}$ and $5 \% \mathrm{CO}_{2}$, which was expected to reduce the concentration of $\mathrm{O}_{2}$ to levels similar to those reported by Nuñez et al (19). In addition, each experiment based on the acute hypoxia model of MA segment included three independent replicates and the preparation of the arteries was performed according to Lee et al (21).

Tight-seal whole-cell patch clamp recording. As described in a previous study (22), $0.4 \mathrm{~mm}$ is the standard length of MRA for tight-seal whole-cell patch clamp recording. In general, the shorter the blood vessel, the smaller the adverse effects for the clamping space. In addition, an average length of $0.4 \mathrm{~mm}$ for the MRA was selected in order to maintain the voltage stability of patch clamp and thus ensuring the accuracy of results. Following exposure to 5 min acute hypoxia the MRA was transferred to a glass-bottomed Petri dish filled with an aerated external solution composed of (mM): $\mathrm{NaCl} 138, \mathrm{KCl} 5$, $\mathrm{CaCl}_{2} 1.6, \mathrm{MgCl}_{2} 1.2$, Na-HEPES 5, HEPES 6 and glucose 7.5. The preparation was secured at the bottom of the dish using the weight of a platinum strip at each end and digested with collagenase A $(1 \mathrm{mg} / \mathrm{ml})$ dissolved in the external solution at $37^{\circ} \mathrm{C}$ for $15 \mathrm{~min}$. The collagenase A digestion was used only for the patch clamp recording and was to expose the smooth muscle cells and avoid the adverse effect of adventitial connective tissue on membrane current. In addition, the two ends of MRA segment were secured at the bottom of the dish using a platinum strip and thus making it difficult for the collagenase is to enter into the vascular lumen. The enzyme was washed away gently twice with external solution and the MRA segment was further cleaned to remove the adventitial tissue. The Petri dish was then placed onto the stage of an inverted microscope equipped with micromanipulators. The specimen was continuously superfused with the external solution $(0.2 \mathrm{ml} / \mathrm{min})$ at room temperature $\left(22-25^{\circ} \mathrm{C}\right)$.

Conventional whole-cell recordings were performed using an Axon 700B amplifier (Axon Instruments; Molecular Devices, LLC, Sunnyvale, CA, USA) as described previously (23). Recording pipettes were pulled from borosilicate 
glass capillaries with filaments using a P-97 puller (Sutter Instrument, Novato, CA, USA). The pipette typically had a resistance of $\sim 5 \mathrm{M} \Omega$ subsequent to being filled with internal solution containing the following $(\mathrm{mM})$ : K-gluconate 130 , $\mathrm{NaCl} 10, \mathrm{CaCl}_{2} 2, \mathrm{MgCl}_{2}$ 1.2, HEPES 10 , ethylene glycol-bis (b-aminoethylether) N,N',N'-tetraacetic acid 5 and glucose 7.5. The membrane current or voltage signal was low-pass filtered at $10 \mathrm{kHz}$; the data were recorded on a PC equipped with a Digidata 1440A AD-interface and pClamp 10.2 software (Axon Instruments; Molecular Devices) at a sampling interval of 10, 20 or 100 msec. A Minidigi digitizer and Axoscope 10.2 software (Axon Instruments; Molecular Devices) were used to simultaneously perform gap-free recording at a sampling interval of $50 \mathrm{msec}$.

The seal resistance usually reached $1-20 \mathrm{G} \Omega$ prior to the rupture of the membrane. Membrane rupture was achieved by a high-frequency buzz current and/or suction pressure from the pipette. The transient current over the membrane input capacitance $\left(\mathrm{C}_{\text {input }}\right)$ was routinely uncompensated to monitor and calculate the access resistance $\left(R_{a}\right)$ and the membrane parameters on- or off-line.

Pressure myographic. The isolated MRA vascular segments were rapidly removed and pinned in a dissecting dish filled with aerated $4^{\circ} \mathrm{C}$ physiological salt solution (PSS) containing (mM): $\mathrm{NaCl} 118.9, \mathrm{KCl} 4.7, \mathrm{MgSO}_{4} 1.2, \mathrm{KH}_{2} \mathrm{PO}_{4} 1.2, \mathrm{CaCl}_{2}$ $2.5, \mathrm{NaHCO}_{3} 25$ and glucose 11. The arteries were cannulated at their ends with glass micropipettes $(1.2 \mathrm{~mm}$; World Precision Instruments, LLC, Sarasota, FL, USA), which were pulled to 300 to $400 \mu \mathrm{m}$ in diameter for the MRA and secured using a 11-0 nylon monofilament suture. At all times, care was taken to avoid excessive tension or stretching of the vascular tissues during dissection. Once the tissues were mounted, the vessel and the perfusion chamber were transferred to an inverted trinocular microscope equipped with an analog video camera and computer-assisted image capture system (Pressure Myograph System; Danish Myo Technology A/S, Aarhus, Denmark) (24) to continuously record the outer diameter of the MRA. The bath temperature was held constant at $37^{\circ} \mathrm{C}$ and was continuously monitored with a thermal microprobe placed immediately adjacent to the mounted vessel. The chamber was superfused at $1.5 \mathrm{ml} / \mathrm{min}$ with warmed and aerated physiologic salt solution $\left(\mathrm{pH} 7.4\right.$, aerated with $95 \% \mathrm{O}_{2}$ and $5 \% \mathrm{CO}_{2}$ for the control group and $5 \% \mathrm{O}_{2}$ and $95 \% \mathrm{~N}_{2}$ for the hypoxiagroup) and maintained at $37^{\circ} \mathrm{C}$. The MRA segments were pressurized with a stepwise increase in transmural pressure that was applied in $10 \mathrm{mmHg}$ increments up to the appropriate working pressure $(60 \mathrm{mmHg})$ with $5 \mathrm{~min}$ of equilibration at each pressure, according to requirement. All experiments were performed under conditions of zero intraluminal flow. The bath was changed to a recirculating buffer circuit (total volume $20 \mathrm{ml}$ ) for treatment with various drugs. The diameter was continuously determined by a video dimension analyzer and recorded using a DMT Vessel Acquisition Suite (Danish Myo Technology A/S). Cumulative dose-response curves to phenylephrine (PE; 0.1-100 $\mu \mathrm{M}$ ) were generated (24).

Western blot analysis. The MRA segments were homogenized in RIPA buffer (at a ratio of $10 \mathrm{mg}$ of tissue to $100 \mu 1$ of RIPA buffer) with freshly added protease inhibitor phenylmethylsulfonyl fluoride. The homogenates were incubated at $4^{\circ} \mathrm{C}$ for $30 \mathrm{~min}$ and centrifuged at $12,000 \times \mathrm{g}$ for $15 \mathrm{~min}$ at $4^{\circ} \mathrm{C}$. The supernatant was collected and the protein concentration in the supernatant was determined. Protein aliquots $(40 \mathrm{mg}$ ) were subjected to $4-15 \%$ tris-glycine denaturing gradient gel electrophoresis. The proteins were then transferred onto a PVDF membrane (EMD Millipore, Billerica, MA, USA). The membrane was hybridized with specific primary antibodies against Cxs $(1: 1,000)$ at $4^{\circ} \mathrm{C}$ overnight. Subsequently, the membrane was incubated with appropriated horseradish peroxidase-conjugated secondary antibodies (1:10,000) (Beijing Zhongshan Jinqiao Biotechnology Co., Ltd., Beijing, China) at room temperature for $2 \mathrm{~h}$. Immunoreactive bands were detected using the ECL chemiluminescence reagent (GE Healthcare Life Sciences, Chalfont, UK). The membrane was stripped following the manufacturer's protocol and labeled with $\beta$-actin antibody (catalog no. ab8226; 1:1,000; Abcam, Cambridge, MA, USA) as an internal control. The intensities of the protein bands were analyzed using Quantity One software (Bio-Rad, Hercules, CA, USA).

Sources of reagents. $\mathrm{Cx} 45$ and $\mathrm{Cx} 43$ primary antibodies were obtained from Abcam (catalog no. ab79010 and ab78408 for anti-Cx43 antibody and anti-Cx45 antibody, respectively), the horseradish peroxidase-conjugated secondary antibody was obtained from Beijing Zhongshan Jinqiao Biotechnology Co., Ltd. The bicinchoninic acid protein assay kit was purchased from Pierce (Thermo Fisher Scientific, Inc., Waltham, MA, USA). RIPA buffer, PE and 2-aminoethoxydiphenyl borate (2-APB; a GJ inhibitor) were purchased from Sigma-Aldrich (Merck KgaA). 2-APB was dissolved in dimethyl sulfoxide as a stock solution prior to being further diluted with the external solution to achieve the final concentrations. The final dimethyl sulfoxide concentration in solution was $\leq 0.1 \%$, which had no detectable effect on vasomotor activity.

Statistical analysis. The rats were age matched to minimize individual differences. The results are expressed at the mean \pm standard error of the mean. For PE-induced vascular reactivity experiments, vasoconstriction effects were calculated using the following equation: [vasoconstriction effect $\left.=\left(D_{\mathrm{PSS}}-\mathrm{D}_{\mathrm{PE}}\right) / \mathrm{D}_{\mathrm{PSS}} \times 100 \%\right]$. $\mathrm{D}_{\mathrm{PSS}}$, the constant vessel diameter in PSS; $\mathrm{D}_{\mathrm{PE}}$, the constant vessel diameter following treatment of PE with different concentrations. Statistical analysis was performed using SPSS version 17.0 (SPSS, Inc., Chicago, IL, USA). The primary statistical analyses were performed using a two-tailed Student's $t$-test or where appropriate by analysis of variance. $\mathrm{P}<0.05$ was considered to indicate a statistically significant difference.

\section{Results}

GJs between MRA VSMCs are suppressed following exposure to acute hypoxia. Compared to constant oxygen perfusion of the VSMCs (normoxia group), acute hypoxia 5 min (a duration of hypoxia $>5$ min would result in the decline of cell activity) significantly decreased the membrane conductance $\left(G_{\text {input }}\right)$ and membrane capacitance $\left(C_{\text {input }}\right)$. However, a marked increase in the membrane resistance $\left(R_{\text {input }}\right)$ and the absolute value of rest 
Table I. Changes of membrane properties of vascular smooth muscle cells in situ in mesenteric resistance artery following hypoxia.

\begin{tabular}{lcccc}
\hline Group & $R_{\text {input }}(\mathrm{M} \Omega)$ & $G_{\text {input }}(\mathrm{nS})$ & $C_{\text {input }}(\mathrm{pF})$ & $\mathrm{RP}(\mathrm{mV})$ \\
\hline Control & $397 \pm 68$ & $2.27 \pm 0.43$ & $201.6 \pm 83.0$ & $-22.1 \pm 1.5$ \\
Hypoxia & $2,365 \pm 340^{\mathrm{a}}$ & $0.49 \pm 0.07^{\mathrm{a}}$ & $19.3 \pm 3.4^{\mathrm{b}}$ & $-44.5 \pm 2.9^{\mathrm{a}}$ \\
Reoxygenation & $566 \pm 124$ & $2.71 \pm 0.46$ & $167.4 \pm 96.1$ & $-25.8 \pm 1.1$ \\
\hline
\end{tabular}

Data are presented as the mean \pm standard error, $\mathrm{n}=13$. ${ }^{\mathrm{a}} \mathrm{P}<0.05,{ }^{\mathrm{b}} \mathrm{P}<0.01 \mathrm{vs}$. control group. Rinput, membrane resistance; Ginput, membrane conductance; Cinput, membrane input capacitance; RP, rest potential.

potential was observed in the VSMCs of the acute hypoxia compared with the normoxia group $(n=13$; Table I).

Acute hypoxia attenuates vasoconstriction of MRAs via decreased GJ communication. Vasoconstrictor responses are Cx dependent, particularly in non-denuded preparations (11). To examine the effects of acute hypoxia on the smooth muscle dependent vasomotor responses, PE was applied to the MRAs of acute hypoxia and normoxia rats. PE (0.1-100 $\mu \mathrm{M})$ initiated concentration-dependent vasoconstriction of the MRAs of normoxia rats $\left(\mathrm{EC}_{50}=3.77 \mu \mathrm{M}\right)$ and acute hypoxia rats $\left(\mathrm{EC}_{50}=4.11 \mu \mathrm{M}\right.$ for $20 \mathrm{~min}, \mathrm{EC}_{50}=3.99 \mu \mathrm{M}$ for $40 \mathrm{~min}$, $\mathrm{EC}_{50}=4.48 \mu \mathrm{M}$ for $\left.60 \mathrm{~min}\right)$. PE $(1-100 \mu \mathrm{M})$ induced more pronounced vasoconstriction in normoxia vs. acute hypoxia rats. ( $\mathrm{n}=7$; $\mathrm{P}<0.01$; Fig. $1 \mathrm{~A})$.

In addition, to confirm whether the GJ was involved in the process that acute hypoxia suppressed PE $(0.1-100 \mu \mathrm{M})$ initiated concentration-dependent vasoconstriction, the effect of GJ inhibitor 2-APB (100 $\mu \mathrm{M}$ for $20 \mathrm{~min})$ on PE-induced vasoconstriction in MRA under normoxia and acute hypoxia was also investigated. Pre-incubation with 2-APB shifted the concentration-response curve of PE-induced vasoconstriction downward (Fig. 1B). The inhibitory effects of 2-APB on the vasoconstriction induced by $\mathrm{PE}(1-100 \mu \mathrm{M})$ were greater in the normoxia compared with the acute hypoxia rats $(\mathrm{n}=9 ; \mathrm{P}<0.05)$.

Acute hypoxia for 20, 40 and 60 min inhibited the frequency of contraction. The diameter of the MRAs was $366.6 \pm 11.5 \mu \mathrm{m}$ $(n=16)$ and no difference was observed between the MRA of acute hypoxia for 20,40 and $60 \mathrm{~min}$. The vasoconstrictor PE $(0.1-100 \mu \mathrm{M})$ was applied to the MRAs of SD rats and constricted the blood vessels to a stable state exhibiting spontaneously vascular vasomotor activity. The frequency was $1.52 \pm 0.11$ per $\min (n=16)$ and the amplitude $27.35 \pm 1.21$ per $\min (n=18)$. Acute hypoxia for 20, 40 and $60 \mathrm{~min}$ PE-induced vasomotion frequencies were $0.57 \pm 0.08(n=6), 0.40 \pm 0.05(n=4)$ and $0.35 \pm 0.07$ $(n=4)$, and the amplitudes were 19.52 $\pm 1.29(n=6), 13.36 \pm 1.71$ $(n=4)$ and $12.00 \pm 1.46(n=4)$, respectively. The frequency and amplitude were significantly reduced in acute hypoxia for 20 , 40 and 60 min vs. the control group $(\mathrm{P}<0.01$; Fig. 2$)$.

Inhibited vascular Cx43 and Cx45 expression in the MRA of acute hypoxia in vessels in vitro. It has been reported that the expression of Cx43 is decreased in myocardial cells (25) and periodontalligament cells (26). In the present study, the protein expression of $\mathrm{Cx} 43$ and $\mathrm{Cx} 45$ in the MRAs of acute hypoxia
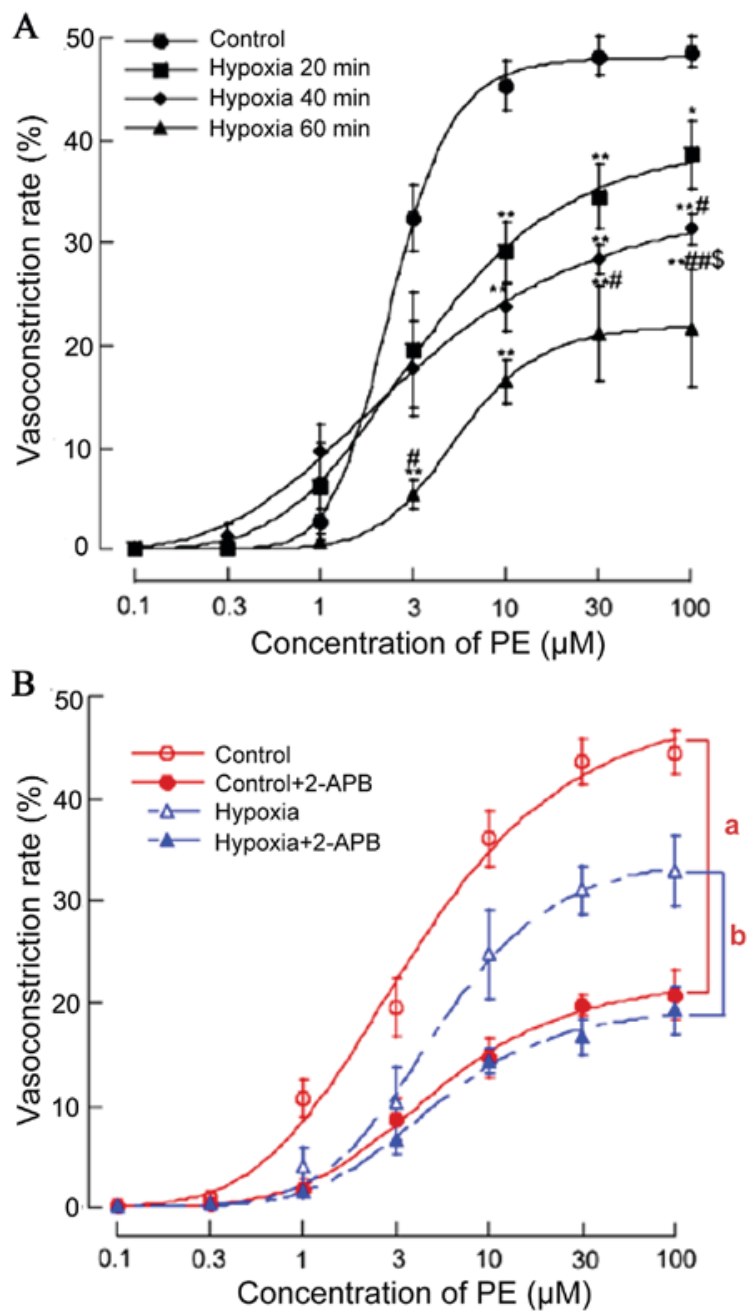

Figure 1. The PE-induced vasoconstriction of MRA under normal and acute hypoxia conditions. (A) PE-induced vasoconstriction with treatment for hypoxia for 20, 40 and $60 \mathrm{~min}$. All data points are from 7 MRAs. ${ }^{*} \mathrm{P}<0.05$, ${ }^{* *} \mathrm{P}<0.01$ vs. normal MRA; ${ }^{\#} \mathrm{P}<0.05,{ }^{\# \#} \mathrm{P}<0.01$ vs. hypoxia $20 \mathrm{~min}$ MRA; ${ }^{\$} \mathrm{P}<0.05$ vs. hypoxia 40 min MRA. (B) The effects of 2-aminoethoxydiphenyl borate on PE-induced vasoconstriction in normal and acute hypoxia MRAs, vasoconstriction was inhibited in normal and hypoxic MRAs, however it was more pronounced in normal MRAs. All data points are from 9 MRAs; ${ }^{\mathrm{a}} \mathrm{P}<0.01$, normal vs. normal+2-APB; ${ }^{\text {b }} \mathrm{P}<0.01$, hypoxia vs. hypoxia+2-APB. $\mathrm{PE}$, phenylephrine; MRA, mesenteric resistance artery.

$1 \mathrm{~h}$ was notable lower compared with control MRAs (Fig. 3). Therefore, acute hypoxia may inhibit the expression of Cxs and the performance of GJ communication, thus resulting in vasomotor dysfunction. 

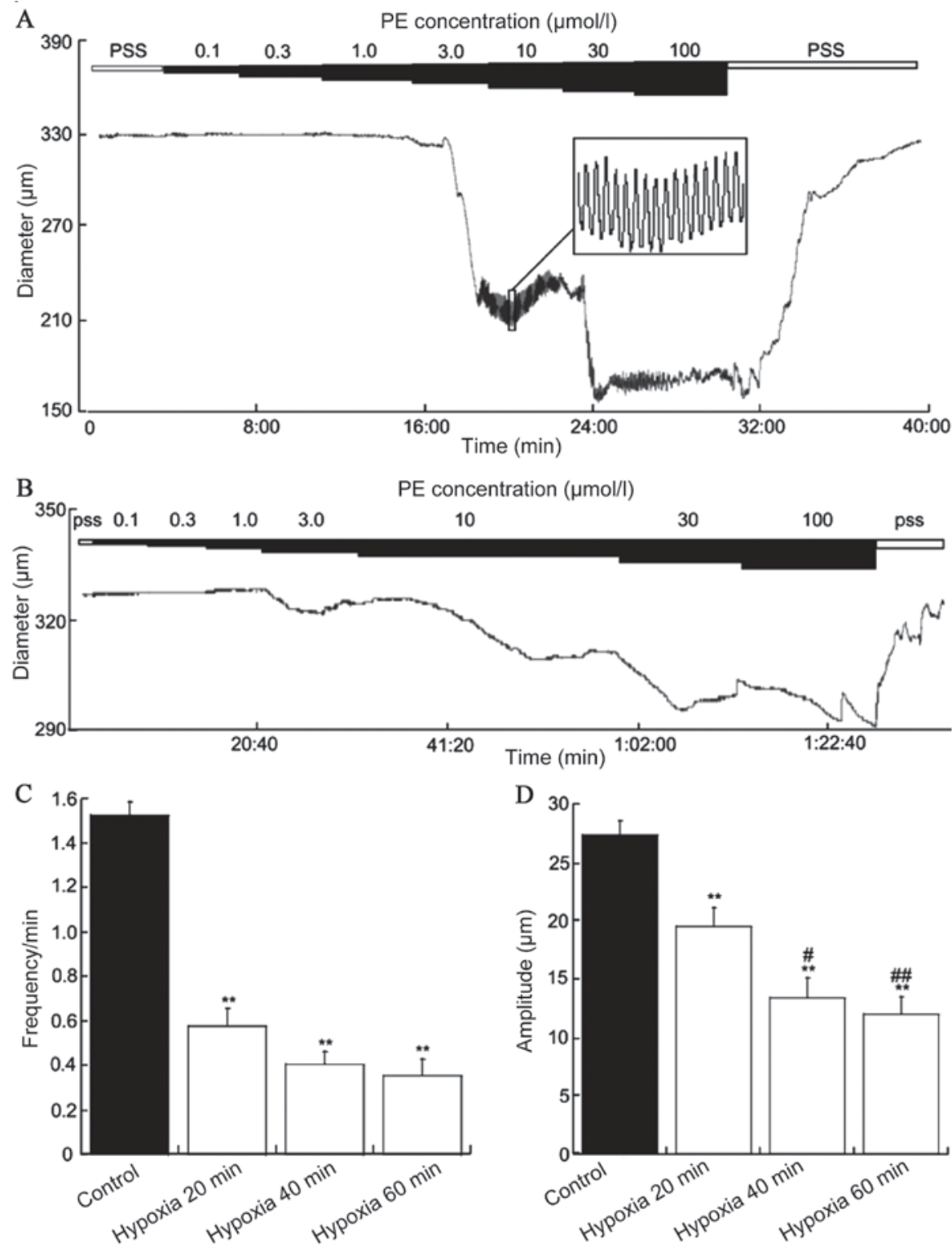

Figure 2. Frequency and amplitude of vasomotion of MRA with treatment for normoxia and hypoxia 20,40 and 60 min. (A) Control; (B) hypoxia 20 min; (C) vasomotion frequency; and (D) vasomotion amplitude of MRA of control and hypoxia 20,40 and 60 min groups. All data points are from 7 MRAs.* $<<0.01$ vs. normoxia MRAs; ${ }^{\# /} \mathrm{P}<0.01$ vs. acute hypoxia 20 min MRAs. MRA, mesenteric resistance artery; PE, phenylephrine.

\section{Discussion}

The present study investigated the association between changes in Cx43/45 expression and vasomotor function, and Cx43/45-mediated GJIC under acute hypoxic conditions in $\mathrm{SD}$ rat MRAs. The key finding of the present study is that the down regulation of $\mathrm{Cx} 43$ and $\mathrm{Cx} 45$ expression had a positive correlation with the reduction of GJIC and vasomotor tone during acute hypoxia, which was reflected in the capacitance/conductance and the frequency/amplitude of vasomotion in vitro, respectively.

Several reports (27-30) have demonstrated that GJ permeability in the cardiomyocytes and astrocytes is reduced by hypoxia/ischemia. A 77\% reduction and $90-95 \%$ reduction in GJIC was observed in astrocytes following $15 \mathrm{~min}$ and $30 \mathrm{~min}$ of hypoxia, respectively (29). A previous study identified that acute hypoxia caused vascular hyperpolarization and vasodilation in the guinea-pig anterior inferior cerebellar artery by increasing outward current and decreasing the GJs of the VSMCs (31). The reduction in the number of GJs or the reduction of conductance of each GJ may inhibit overall GJIC and the two appear to be involved in hypoxia/ischemia-induced inhibition of GJIC (14). In the present study, whole-cell recordings from the VSMCs embedded in a segment of the MRA were used to detect GJ communication in normoxia and acute hypoxia vessels. This novel technique was practicable for determining the function of GJs between the VSMCs in a more physiologically relevant state (compared with dispersed VSMCs) (32). The results indicated that whole-cell recording from embedded VSMCs in arteriole segments is an accessible approach that can be used to study various arteriolar preparations electrophysiologically $(33,34)$. In Table I, the membrane capacitance and conductance of the VSMCs of the MRAs in acute hypoxia rats were significantly reduced compared with normoxia rats, which is in agreement with previous studies in cardiomyocytes and astrocytes, namely that hypoxia may 
Cx43

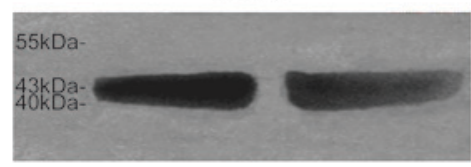

$\beta$-actin
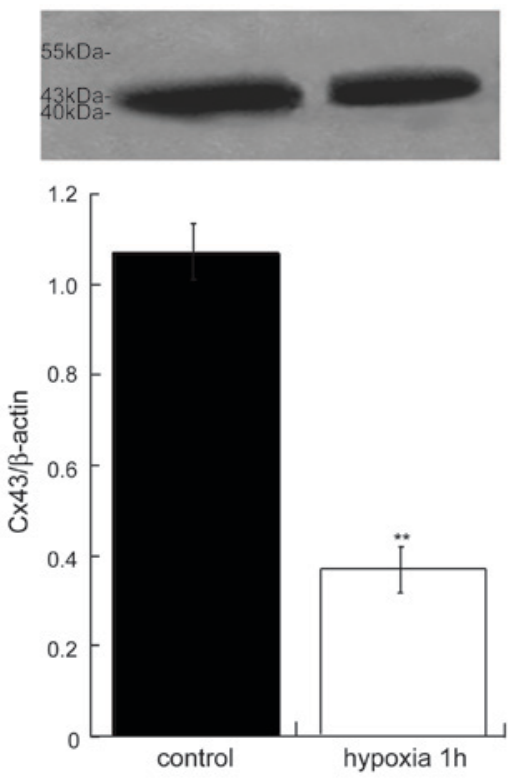

Cx45

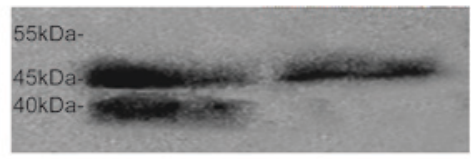

$\beta$-actin
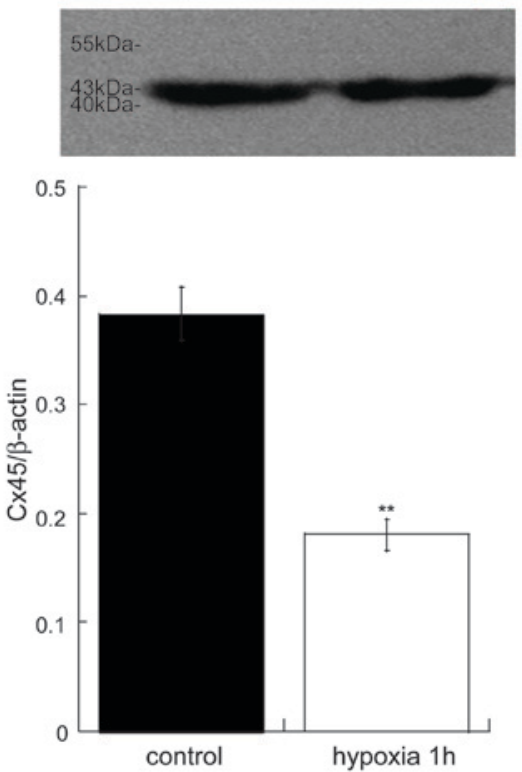

Figure 3. Expression of $\mathrm{Cx} 45$ and $\mathrm{Cx} 43$ in mesenteric resistance artery of Sprague-Dawley rats in normoxia and acute hypoxia $1 \mathrm{~h} .{ }^{* *} \mathrm{P}<0.01 \mathrm{vs}$. normoxia MRAs. Cx, connexin.

suppress GJIC. The reduction of the electrical coupling of GJs is often associated with dephosphorylation and phosphorylation of Cxs $(12,14,35)$. In the normal cardiovascular system, the majority of the Cxs are phosphorylated $(15,17)$. Phosphorylation of Cxs serves important functions in GJ assembly, channel gating and degradation. There are certain phosphorylation sites where phosphorylated Cxs may increase GJ assembly whereas others may inhibit formation of GJs, or reduce the channel opening time (36). For example, acute hypoxia (5-40 min) can induce $\mathrm{Cx} 43$ dephosphorylation and reduce junctional uncoupling in astrocytes and hearts $(15,37)$, while increasing Cx43-serine 368 phosphorylation status $(16,38)$ has been demonstrated to change the status of $\mathrm{Cx} 43$ channels from open to closed (16). The change of phosphorylation status may affect the number of GJs and conductance of GJs $(39,40)$. In support of this, a possible explanation is that hypoxia suppresses electrical coupling of adjacent VSMCs in MRA, perhaps through dephosphorylation or serine 368 phosphorylation of Cxs. The present study hypothesizes that the phosphorylation state of Cx43 is altered by hypoxia and thus affects channel opening. It is aimed that future studies will investigate which specific phosphorylation sites of $\mathrm{Cx} 43$ are affected by acute hypoxia in MRA using mass spectrometry. The expression or localization of nonphosphorylated and phosphorylated Cxs during acute hypoxia exposure by western blot analysis or immunofluorescent staining will be analyzed as the subject of a future study.

The phosphorylation state of Cxs affects their half-lives. Previous studies have suggested that the phosphorylation of specific serine sites on $\mathrm{Cx} 43$ and $\mathrm{Cx} 45$ result in Cx degradation by complex mechanisms (41-43). Phosphorylation of $\mathrm{Cx} 43$ on serine 255 by p34cdc 2 kinase in Rat1 cells promotes the degradation of Cx43 (42). Thus, the phosphorylation state of serine residues may also alter $\mathrm{Cx}$ stability and/or target the protein for degradation (41). In the current study, the expression of Cx43 and $\mathrm{Cx} 45$ were significantly reduced by acute hypoxia for $1 \mathrm{~h}$; this may result from the alteration of the phosphorylation state of Cx43 and Cx45 promoting their degradation.

Oxygen deprivation during hypoxic exposure causes the intracellular accumulation of toxic metabolic products and ATP depletion, which can lead to cell injury or death (44); GJ and hemi-channels serve a role in the communication of cell death signals between cells (45). Faigle et al (16) demonstrated that ATP release was significantly attenuated (2\% oxygen, $22 \pm 3 \%$ after $48 \mathrm{~h}$ ) by the selective repression of $\mathrm{Cx} 43$ transcription and time-dependent $\mathrm{Cx} 43$ total and surface protein repression during hypoxia. The GJs may transmit death signals between injured and intact cells or lead to ATP loss and cell death via the opening of GJ or Cx hemi-channels. The uncoupling of GJ and the closing of the GJ channel during hypoxia may promote cell survival and thus limit cell necrosis.

Electrical coupling of GJs in the VSMCs serves a crucial role in the synchronization and coordination of vasomotor tone (9). Ischemia or hypoxia can cause systemic vascular system relaxation with the exception of the pulmonary artery $(6,46)$. Following exposure to hypoxic conditions, the cardiomyocytes shorten to reduce contraction and increase the resistance of the whole tissue $(17,47)$. Following these studies, the present study ascertained the effect of acute 
hypoxia on the vasoconstriction of the MRAs and the role of GJs in the regulation of vasomotor tone of MRAs during hypoxia. In agreement with previous data, the PE-induced maximal vasoconstrictive responses in MRAs were less sensitive in the acute hypoxia compared with the normoxia group (Fig. 1A). As the experiments in the current study were designed to study the role of GJs in the regulation of vasomotor tone of MRAs during hypoxia, a pharmacological procedure with GJ blocker 2-APB was used to inhibit GJ. 2-APB is a membrane permeable modulator of myo-inositol 1,4,5-triphosphate $\left(\mathrm{IP}_{3}\right)$ receptors and has been of widespread recent use in the inhibition or activation of transient receptor potential (TRP) channels and the blocking of GJ channels (48). 2-APB was previously reported to exert opposite effects on members of TRP channels, inhibiting activity of TRP5 and TRP6 at $20 \mu \mathrm{M}$ and activating TRP cation channel subfamily V member (TRPV)-1, TRPV2 and TRPV3 at higher concentrations $(48,49)$. Pan et al $(50)$, in the screening of GJ antagonists, identified that 2-APB was one of the most effective antagonists, completely blocking A-type horizontal cell coupling in rabbit retina. 2-APB at higher concentrations $(100 \mu \mathrm{M})$ was used as a specific GJ channel blocker in critical control experiments demonstrating peptide permeation through GJs (51) and at $10 \mu \mathrm{M}$ to disrupt GJIC in the vascular wall (52). Although 2-APB blocks slow $\mathrm{Ca}^{2+}$ waves in the process of blockading the $\mathrm{IP}_{3}$ receptor, it should be noted that the results above may be a result of GJ channel blocking. For example, a previous study (53) demonstrated the blockade of urinary bladder smooth muscle calcium waves by 2-APB and other GJ blockers, however no intracellular $\mathrm{Ca}^{2+}$ release effect was observed when using thapsigargin and xestospongin. In addition, the results of a study by Li et al (54) also demonstrated that 2-APB may mimic the effects of inhibition of gap communication by Gap 27 and lead to a significant inhibition of lucifer yellow uptake and the attenuation of calcium transients in ventricular myocytes. In the present study, the inhibitory effects of 2-APB on PE-induced (1-100 $\mu \mathrm{M})$ vasoconstriction were greater in normoxia compared with acute hypoxia rats (Fig. 1B). It is therefore hypothesized that a blocking of gap communication by2-APB may be expected as a consequence of GJ channel blockade. The changes in contractile response in the MRA were directly associated with the uncoupling of GJs and the reduction in electrophysiological properties of the VSMCs in MRA under hypoxic conditions and suggest that GJ intercellular communication was inhibited by acute hypoxia and thus led to the reduction of vasoconstriction in response to PE. The data from the present study indicated that the inhibitory effect of 2-APB on PE-induced vasoconstriction was markedly less apparent in acute hypoxia rats compared with the normoxia control (Fig. 1B). These changes in contractile response in MRAs were directly associated with the uncoupling of GJs and the reduction in the electrophysiological properties of the VSMCs in MRAs under hypoxic conditions.

These results, together with the reduction of electrical coupling in MRAs, demonstrated that the regulation of GJ coupling is involved in the vasodilatation improvement in response to hypoxia conditions. Furthermore, previous studies have demonstrated that GJs have a crucial role in coordinating the synchronization of vasomotor tone by synchronizing the changes in cytoplasmic $\mathrm{Ca}^{2+}$ between VSMCs (55). A plausible explanation for the reduction of vasoconstriction in MRAs during the condition of acute hypoxia is that inhibited GJs reduce intercellular $\mathrm{Ca}^{2+}$ wave propagation between the VSMCs of MRAs, which leads to the response of vasomotion being less in acute hypoxia rats compared with the normoxia controls.

Subsequent experiments indicated that decreased vasoconstriction of MRA during acute hypoxic exposure was associated with the reduction of $\mathrm{Cx} 43$ and $\mathrm{Cx} 45$ expression. In the heart, the expression of $\mathrm{Cx} 43$ depends on the duration of hypoxia (18). Wu et al (18) demonstrated that cultured atrial cells in hypoxia for 6 and $12 \mathrm{~h}$ experienced a decrease in the Cx43 expression by $\sim 30-50 \%$. In the present study, exposure to acute hypoxia for only $1 \mathrm{~h}$ cause a significant decrease in $\mathrm{Cx} 43$ and $\mathrm{Cx} 45$ expression. A reduction in $\mathrm{Cx} 43$ and $\mathrm{Cx} 45$ expression may lead to the reduction of GJIC in VSMCs, thereby influencing the electrical uncoupling of MRA in a low-oxygen environment. The role of Cx43 channels in hypoxia-induced cell injury or death has been studied in several organs, including the heart and the brain $(12,44)$. Cx43 in cardiomyocyte mitochondria functions as a key regulator of cell protection against hypoxia induced cell apoptosis (12). In previous study, Martins-Marques et al (13) demonstrated that ischemia results in Cx43 ubiquitin-dependent degradation localized at the intercalated discs, which may be a novel regulatory pathway in GJ remodeling associated with hypoxia/ischemia injury. A similar mechanism of ubiquitin-dependent degradation may occur in the present study and thus resulting in the down regulation of $\mathrm{Cx} 43$ or Cx45 expression, although the degradation of $\mathrm{Cx} 43$ and $\mathrm{Cx} 45$ during acute hypoxia exposure was not assessed. In contrast with $\mathrm{Cx} 43$, the physiological functions of $\mathrm{Cx} 45$ remain unclear, although its expression has been demonstrated in vascular smooth muscle $(56,57)$. Whether Cx45 hemichannels and/or GJs are important for hypoxia-mediated vascular dysfunction remains to be elucidated. The majority of current studies have failed to establish the functional associations between $\mathrm{Cx} 45$ and hypoxic exposure. In this context, the data from the current study provides evidence that acute hypoxia inhibited the level of Cx45, which may be responsible for the coordinated role of vasomotor tone in mediating cell protection exposure to hypoxia.

Together, the results reported from the present study provide the first evidence that acute hypoxia negatively regulates the vasomotor tone of the vascular smooth muscle layer of the MRA, possibly through downregulation of Cx43 and $\mathrm{Cx} 45$ expression concurrently with the suppression of Cx43- and Cx45-mediated intercellular communications. In summary, the present study defines an important contribution of GJ in regulating vasomotor function during limited oxygen availability, one that may be essential for the adaptation of vasomotor tone in response to acute hypoxia.

\section{Acknowledgements}

The current study was supported by the National Natural Science Foundation of China (grant nos. 31260247 and 31460264 to Professor Ke-Tao Ma, grant no. 81460098 to Dr Xin-Zhi Li and grant no. 81260159 to Dr LiLi). 


\section{References}

1. Wanandi SI, Reni P and Syarifah D: Relative expression of HIF- $1 \alpha$ mRNA in rat heart, brain and blood during induced systemic hypoxia. Makara Seri Sains 13: 185-188, 2009.

2. Lohman AW, Billaud M and Isakson BE: Mechanisms of ATP release and signalling in the blood vessel wall. Cardiovasc Res 95: 269-280, 2012.

3. Ainslie PN, Ogoh S, Burgess K, Celi L, McGrattan K, Peebles K, Murrell C, Subedi P and Burgess KR: Differential effects of acute hypoxia and high altitude on cerebral blood flow velocity and dynamic cerebral auto regulation: alterations with hyperoxia. J Appl Physiol 104: 490-498, 2008.

4. Tawaa M, Shimosato T, Geddawy A, Imamura T and Okamura T: Influence of hypoxia on endothelium-derived no-mediated relaxation in rat carotid, mesenteric and iliac arteries. Pharmacology 91: 322-330, 2013.

5. Zhdanov GG and Sokolov IM: Tissue hypoxia in acute myocardial infarction and possible approaches to its correction. Anesteziol Reanimatol: 51-53, 2001 (In Russian).

6. Ariyaratnam P, Loubani M and Morice AH: Hypoxic pulmonary vasoconstriction in humans. Biomed Res Int 2013: 623684 2013.

7. Wan J, Yamamura A, Zimnicka AM, Voiriot G, Smith KA, Tang H, Ayon RJ, Choudhury MS, Ko EA, Wang J, et al: Chronic hypoxia selectively enhances L- and T-type voltage-dependent $\mathrm{Ca} 2+$ channel activity in pulmonary artery by upregulating Cav1.2 and Cav3.2. Am J Physiol Lung Cell Mol Physiol. 305 L154-L164, 2013.

8. Al-Shraim MM, Zafer MH and Rahman GA: Acute occlusive mesenteric ischemia in high altitude of southwestern region of Saudi Arabia. Ann Afr Med 11: 5-10, 2012.

9. Figueroa XF and Duling BR: Gap junctions in the control of vascular function. Antioxid Redox Signal 11: 251-266, 2009.

10. Rummery NM and Hill CE: Vascular gap junctions and implications for hypertension. Clin Exp Pharmacol Physiol 31: 659-667, 2004.

11. Wang L, Yin J, Nickles HT, Ranke H, Tabuchi A, Hoffmann J, Tabeling C, Barbosa-Sicard E, Chanson M, Kwak BR, et al: Hypoxic pulmonary vasoconstriction requires connexin 40-mediated endothelial signal conduction. J Clin Invest 122: 4218-4230, 2012

12. Waza AA, Andrabi K and Hussain MU: Protein kinase $\mathrm{C}$ (PKC) mediated interaction between conexin43 (Cx43) and $\mathrm{K}(+)$ (ATP) channel subunit (Kir6.1) in cardiomyocyte mitochondria: Implications in cytoprotection against hypoxia induced cell apoptosis. Cell Signal 26: 1909-1917, 2014.

13. Martins-Marques T, Catarino S, Marques C, Matafome $\mathrm{P}$, Ribeiro-Rodrigues T, Baptista R, Pereira P and Girão H: Heart ischemia results in connexin43 ubiquitination localized at the intercalated discs. Biochimie 112: 196-201, 2015.

14. Miura T, Miki T and Yano T: Role of the gap junction in ischemic preconditioning in the heart. Am J Physiol Heart Circ Physiol 298: H1115-H1125, 2010

15. Turner MS, Haywood GA, Andreka P, You L, Martin PE, Evans WH, Webster KA and Bishopric NH: Reversible connexin 43 dephosphorylation during hypoxia and reoxygenation is linked to cellular ATP levels. Circ Res 95: 726-733, 2004

16. Faigle M, Seessle J, Zug S, El Kasmi KC and Eltzschig HK ATP release from vascular endothelia occurs across Cx43 hemichannels and is attenuated during hypoxia. PLoS One 3: e2801, 2008

17. Matsushita S, Kurihara H, Watanabe M, Okada T, Sakai T and Amano A: Alterations of phosphorylation state of connexin 43 during hypoxia and reoxygenation are associated with cardiac function. J Histochem Cytochem 54: 343-353, 2006.

18. Wu X, Huang W, Luo G and Alain LA: Hypoxia induces connexin 43 dysregulation by modulating matrix metalloproteinases via MAPK signaling. Mol Cell Biochem 384: 155-162, 2013.

19. Nuñez C, Victor VM, Martí M and D'Ocon P: Role of endothelial nitric oxide in pulmonary and systemic arteries during hypoxia. Nitric Oxide 15: 17-27, 2014.

20. Ibe JC, Zhou Q, Chen T, Tang H, Yuan JX, Raj JU and Zhou G: Adenosine monophosphate-activated protein kinase is required for pulmonary artery smooth muscle cell survival and the development of hypoxic pulmonary hypertension. Am J Respir Cell Mol Biol 49: 609-618, 2013.

21. Lee YH, Seo JH and Kang BS: Effects of hypoxia on pulmonary vascular contractility. Yonsei Med J 39: 261-267, 1998.
22. Ma KT, Li XZ, Li L, Jiang XW, Chen XY, Liu WD, Zhao L, Zhang ZS and Si JQ: Role of gap junctions in the contractile response to agonists in the mesenteric artery of spontaneously hypertensive rats. Hypertens Res 37: 110-115, 2014.

23. Ma KT, Guan BC, Yang YQ, Nuttall AL and Jiang ZG: 2-Aminoethoxydiphenyl borate blocks electrical coupling and inhibits voltage-gated $\mathrm{K}+$ channels in guinea pig arteriole cells. Am J Physiol Heart Circ Physiol 300: H335-H346, 2011

24. Li L, Wang R, Ma KT, Li XZ, Zhang CL, Liu WD, Zhao L and Si JQ: Differential effect of calcium-activated potassium and chloride channels on rat basilar artery vasomotion. J Huazhong Univ Sci Technolog Med Sci 34: 482-490, 2014.

25. Wang R, Zhang C, Ruan Y, Liu N and Wang L: Change in phosphorylation of connexin 43 during acute hypoxia and effects of antiarrhythmic peptide on the phosphorylation. J Huazhong Univ Sci Technolog Med Sci 27: 241-244, 2007.

26. Kato R, Ishihara Y, Kawanabe N, Sumiyoshi K, Yoshikawa Y, Nakamura M,Imai Y, Yanagita T, Fukushima H, Kamioka H, et al: Gap-junction-mediated communication in human periodontal ligament cells. J Dent Res 92: 635-640, 2013

27. Naitoh K, Yano T, Miura T, Itoh T, Miki T, Tanno M, Sato T, Hotta H,Terashima Y and Shimamoto K: Roles of Cx43-associated protein kinases in suppression of gap junction-mediated chemical coupling by ischemic preconditioning. Am J Physiol Heart Circ Physiol 296: H396-H403, 2009.

28. Sato M, Jiao Q, Honda T, Kurotani R, Toyota E, Okumura S, Takeya T, Minamisawa S, Lanier SM and Ishikawa Y: Activator of $\mathrm{G}$ protein signaling 8 (AGS8) is required for hypoxia-induced apoptosis of cardiomyocytes: Role of $\mathrm{G}$ betagamma and connexin 43 (Cx43). J Biol Chem 284: 31431-31440, 2009.

29. Li WE and Nagy JI: Connexin 43 phosphorylation state and intercellular communication in cultured astrocytes following hypoxia and protein phosphatase inhibition. Eur J Neurosci 12: 2644-2650, 2000.

30. Li W, Hertzberg EL and Spray DC: Regulation of connexin43-protein binding in astrocytes in response to chemical ischemia/hypoxia. J Biol Chem 280: 7941-7948, 2005.

31. Li XZ, Si JQ, Zhang ZS, Zhao L, Li L and Ma KT: Acute hypoxia increases outward current and decreases gap junction of VSMCs in guinea-pig anterior inferior cerebellar artery. Sheng Li Xue Bao 63: 533-539, 2011 (In Chinese).

32. Guan BC, Si JQ and Jiang ZG: Blockade of gap junction coupling by glycyrrhetinic acids in guinea pig cochlear artery: A whole-cell voltage- and current-clamp study. Br J Pharmacol 151: 1049-1060, 2007.

33. Quinn K and Beech DJ: A method for direct patch-clamp recording from smooth muscle cells embedded in functional brain microvessels. Pflugers Arch 435: 564-569, 1998.

34. Yamamoto Y, Fukuta H, Nakahira Y and Suzuki H: Blockade by 18beta-glycyrrhetinic acid of intercellular electrical coupling in guinea-pig arterioles. J Physiol 511: 501-508, 1998.

35. Beardslee MA, Lerner DL, Tadros PN, Laing JG, Beyer EC, Yamada KA, Kléber AG, Schuessler RB and Saffitz JE: Dephosphorylation and intracellular redistribution of ventricular connexin43 during electrical uncoupling induced by ischemia. Circ Res 87: 656-662, 2000.

36. Solan JL and Lampe PD: Connexin43 phosphorylation: Structural changes and biological effects. Biochem J 419: 261-272, 2009

37. Le HT, Sin WC, Lozinsky S, Bechberger J, Vega JL, Guo XQ, Sáez JC and Naus CC: Gap junction intercellular communication mediated by connexin43 in astrocytes is essential for their resistance to oxidative stress. J Biol Chem 289: 1345-1354, 2014.

38. Srisakuldee W, Makazan Z, Nickel BE, Zhang F, Thliveris JA, Pasumarthi KB and Kardami E: The FGF-2-triggered protection of cardiac subsarcolemmal mitochondria from calcium overload is mitochondrial connexin 43-dependent. Cardiovasc Res 103: 72-80, 2014.

39. Shimizu K and Stopfer M: Gap junctions. Curr Biol 23: R1026-R1031, 2013.

40. Goodenough DA and Paul DL: Gap Junctions. Cold Spring Harb Perspect Biol 1: a002576, 2009.

41. Saffitz JE, Laing JG and Yamada KA: Connexin expression and turnover: Implications for cardiac excitability. Circ Res 86: 723-728, 2000.

42. Lampe PD, Kurata WE, Warn-Cramer BJ and Lau AF: Formation of a distinct connexin43 phosphoisoform in mitotic cells is dependent upon p34cdc2 kinase. J Cell Sci 111: 833-841, 1998. 
43. Hertlein B, Butterweck A, Haubrich S, Willecke K and Traub O Phosphorylated carboxy terminal serine residues stabilize the mouse gap junction protein connexin45 against degradation. J Membr Biol 162: 247-257, 1998.

44. Wang X, Ma A, Zhu W, Zhu L, Zhao Y, Xi J, Zhang X and Zhao B: The role of connexin 43 and hemichannels correlated with the astrocytic death following ischemia/reperfusion insult. Cell Mol Neurobiol 33: 401-410, 2013.

45. Krysko DV, Leybaert L, Vandenabeele P and D'Herde K: Gap junctions and the propagation of cell survival and cell death signals. Apoptosis 10: 459-469, 2005.

46. Madden JA, Vadula MS and Kurup VP: Effects of hypoxia and other vasoactive agents on pulmonary and cerebral artery smooth muscle cells. Am J Physiol 263: L384-L393, 1992.

47. Jain SK, Schuessler RB and Saffitz JE: Mechanisms of delayed electrical uncoupling induced by ischemic preconditioning. Circ Res 92: 1138-1144, 2003.

48. Kovacs G, Montalbetti N, Simonin A, Danko T, Balazs B, Zsembery A and Hediger MA: Inhibition of the human epithelial calcium channel TRPV6 by 2-aminoethoxydiphenyl borate (2-APB). Cell Calcium 52: 468-480, 2012.

49. Colton CK and Zhu MX: 2-Aminoethoxydiphenyl borate as a common activator of TRPV1, TRPV2, and TRPV3 channels. Handb Exp Pharmacol 173-187, 2007.

50. Pan F, Mills SL and Massey SC: Screening of gap junction antagonists on dye coupling in the rabbit retina. Vis Neurosci 24 609-618, 2007.
51. Neijssen J, Herberts C, Drijfhout JW, Reits E, Janssen L and Neefjes J: Cross-presentation by intercellular peptide transfer through gap junctions. Nature 434: 83-88, 2005.

52. Griffith TM, Chaytor AT, Bakker LM and Edwards DH: 5-Methyltetrahydrofolate and tetrahydrobiopterin can modulate electrotonically mediated endothelium-dependent vascular relaxation. Proc Natl Acad Sci USA 102: 7008-7013, 2005.

53. Hashitani H, Yanai Y and Suzuki H: Role of interstitial cells and gap junctions in the transmission of spontaneous $\mathrm{Ca} 2+$ signals in detrusor smooth muscles of the guinea-pig urinary bladder. J Physiol 559: 567-581, 2004.

54. Li C, Meng Q, Yu X, Jing X, Xu P and Luo D: Regulatory effect of connexin 43 on basal $\mathrm{Ca} 2+$ signaling in rat ventricular myocytes. PLoS One 7: e36165, 2012.

55. Halidi N, Alonso F, Burt JM, Bény JL, Haefliger JA and Meister JJ: Intercellular calcium waves in primary cultured rat mesenteric smooth muscle cells are mediated by Connexin43. Cell Commun Adhes 19: 25-37, 2012.

56. Kurtz A: Renal connexins and blood pressure. Biochim Biophys Acta 1818: 1903-1908, 2012.

57. Schmidt VJ, Jobs A, von Maltzahn J, Wörsdörfer P, Willecke K and de Wit C: Connexin45 is expressed in vascular smooth muscle but its function remains elusive. PLos One 7: e42287, 2012. 